\title{
PTGS2 polymorphism rs689466 favors breast cancer recurrence in obese patients
}

\author{
Daniely Regina Freitas-Alves, 1,2,3, Hayra de Andrade Vieira-Monteiro1,2, Diogo Nascimento Piranda1,3, \\ Marcelo Sobral-Leite1,4, Taiana Sousa Lopes da Silva1,3,5, Anke Bergmann1, Samuel Santos Valença3, \\ Jamila Alessandra Perini2,6 and Rosane Vianna-Jorge ${ }^{1,2,3}$
}

'Coordenação de Pesquisa, Instituto Nacional do Câncer, Rio de Janeiro, Rio de Janeiro, Brasil

2Programa de Pós-Graduação em Saúde Pública e Meio Ambiente, Escola Nacional de Saúde Pública, FIOCRUZ, Rio de Janeiro, Rio de Janeiro, Brasil IInstituto de Ciências Biomédicas, Universidade Federal do Rio de Janeiro, Rio de Janeiro, Rio de Janeiro, Brasil

${ }^{4}$ Division of Molecular Pathology, The Netherlands Cancer Institute, Amsterdam, The Netherlands

5Programa de Pós-Graduação em Biologia Molecular e Celular, Instituto Biomédico, Universidade Federal do Estado do Rio de Janeiro, Rio de Janeiro,

Rio de Janeiro, Brasil

${ }^{6}$ Laboratório de Pesquisa de Ciências Farmacêuticas, Unidade de Farmácia, Centro Universitário Estadual da Zona Oeste, Rio de Janeiro,

Rio de Janeiro, Brasil

Correspondence should be addressed to R Vianna-Jorge: rosanevj@gmail.com

\begin{abstract}
Breast cancer is the leading cancer among women, and its increasing incidence is a challenge worldwide. Estrogen exposure is the main risk factor, but obesity among postmenopausal women has been shown to favor disease onset and progression. The link between obesity and mammary carcinogenesis involves elevated estrogen production and proinflammatory stimuli within the adipose tissue, with activation of the cyclooxygenase-2 pathway. Here, we evaluate the impact of the four most common cyclooxygenase-2 gene polymorphisms (rs689465, rs689466, rs20417 and rs20417), in combination with obesity, on the risk of breast cancer progression in a cohort of Brazilian breast cancer patients $(N=1038)$. Disease-free survival was evaluated using Kaplan-Meier curves, with multivariate Cox proportional hazards regression models for calculation of adjusted hazard ratios $\left(\mathrm{HR}_{\mathrm{adj}}\right)$. Obesity did not affect disease progression, whereas rs689466 variant genotypes increased the recurrence risk among obese patients $\left(H R_{a d j}=2.5 ; 95 \% \mathrm{Cl}=1.4-4.3\right)$, either for luminal $\left(\mathrm{HR}_{\mathrm{adj}}=2.2 ; 95 \% \mathrm{Cl}=1.1-4.2\right)$ or HER2like and triple-negative tumors $\left(\mathrm{HR}_{\mathrm{adj}}=3.2 ; 95 \% \mathrm{Cl}=1.2-8.5\right)$. Likewise, the haplotype *4, which contains variant $r 569466$, was associated with shorter disease-free survival among obese patients $\left(\mathrm{HR}_{\mathrm{adj}}=3.3 ; 95 \% \mathrm{Cl}=1.8-6.0\right)$, either in luminal $\left(\mathrm{HR}_{\mathrm{adj}}=3.5 ; 95 \%\right.$ $\mathrm{Cl}=1.6-7.3)$ or $\mathrm{HER} 2-$ like and triple-negative $\left(\mathrm{HR}_{\mathrm{adj}}=3.1 ; 95 \% \mathrm{Cl}=1.1-8.9\right)$ tumors. Such deleterious impact of variant rs689466 on disease-free survival of obese breast cancer patients was restricted to postmenopausal women. In conclusion, cyclooxygenase-2 genotyping may add to the prognostic evaluation of obese breast cancer patients.
\end{abstract}

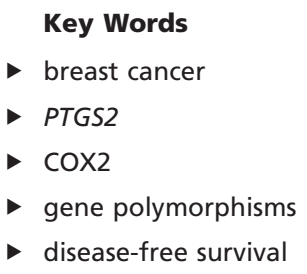

Endocrine-Related Cancer (2018) 25, 351-365

\section{Introduction}

Breast cancer is the leading cancer (Torre et al. 2017) and the first cause of death by cancer among women worldwide (Ferlay et al. 2010). It is a very heterogeneous disease, with diverse morphological and molecular presentations (Dai et al. 2016), resulting in great variability of clinical outcomes, even among early-stage tumors 
(Early Breast Cancer Trialists' Collaborative Group 2005). Although the advances in tumor classification and personalized treatment have contributed to reduce the global mortality of breast cancer, the prognostic evaluation of newly diagnosed tumors remains a clinical challenge, which justifies the continuous search for new biomarkers and staging models.

An additional challenge in the clinical and epidemiological approach of breast cancer is its increasing incidence, both in developed and under-developed countries, which is attributed to changes in life style (Torre et al. 2017). For example, the use of hormonal contraceptives and of menopausal hormone therapy contributes for higher exposure to estrogen, a major risk factor for breast cancer development (Chlebowski et al. 2013). More recently, weight gain after age 18 years and excess body weight among postmenopausal women have also been implicated as breast cancer risk factors (Torre et al. 2017). In addition to favoring breast cancer development, obesity also contributes for worse prognosis, including increased recurrence risk and shorter disease-free and overall survival, independent of tumor stage at diagnosis (Pajares et al. 2013, Chan et al. 2014). The link between excess weight or obesity and breast cancer appears to involve altered expression of hormones, especially estrogen, as well as growth factors, inflammatory cytokines and adipokines, which promote cancer cell survival, metastasis, angiogenesis and decreased cancer cell apoptosis (Crespi et al. 2016).

The main source of estrogen in postmenopausal women is the adipose tissue, the primary site of aromatase expression following menopause (Iyengar et al. 2015). Accordingly, elevated aromatase expression has been reported in the breast tissue of overweight and obese women, where aromatase levels correlate with local inflammation, characterized by the presence of crown-like structures, consisting of necrotic adipocytes surrounded by macrophages (Morris et al. 2011). Crownlike structures are considered as inflammatory foci, as they release several proinflammatory mediators (Mullooly et al. 2017), including the cyclooxygenase-2 (COX2)-derived prostaglandin E2 (PGE2). PGE2 stimulates all of the key features of mammary carcinogenesis including mutagenesis, mitogenesis, angiogenesis, metastasis, inhibition of apoptosis and immunosuppression (Harris 2014). PGE2 is also a potent stimulant of aromatase expression in preadipocytes, the predominant site of aromatase expression within adipose tissue (Morris et al. 2011). This obesity-inflammation-aromatase axis may be a significant contributor to increased mortality rate observed in obese postmenopausal patients, with COX2 pathway apparently playing a central role (Bowers et al. 2014).

Although COX2 has been associated with worse prognosis of breast cancer, its expression in breast tumors presents great variability (Glover et al. 2011). For instance, in invasive breast carcinoma, the frequencies of COX2 overexpression range from $17 \%$ to $84 \%$ (Glover et al. 2011). The mechanisms underlying the regulation of COX2 expression, and the reasons for the great interindividual variability are not yet fully understood.

COX2 is encoded by the prostaglandin-endoperoxidase synthase 2 gene (PTGS2), whose promoter region (PR) encloses several potential regulatory elements (RE) (Tanabe \& Tohnai 2002). Single-nucleotide polymorphisms (SNP) have been described next to these RE (rs689465, rs689466, rs20417) and appear to affect gene transcription (Papafili 2002, Zhang et al. 2005, Sakaki et al. 2010, Pereira et al. 2014). The 3 '-untranslated region (3'-UTR) of PTGS2 also presents potential RE (Appleby et al. 1994), which generate consensus-binding sequences ('AUUUA') for proteins that maintain the stability (Young et al. 2009) or trigger the degradation of mRNA (Dixon 2000). A SNP located in the 3 '-UTR of the PTGS2 gene (rs5275) has been shown to favor mRNA stability and gene expression (Moore et al. 2012). Many studies explored the role of PTGS2 SNPs on the susceptibility to breast cancer, and a meta-analysis suggests an increased risk associated with rs20417 (Li et al. 2015). There are fewer information regarding the impact of PTGS2 SNPs on breast cancer outcomes, and all the available reports explored only rs5275, with no significant results (Abraham et al. 2009, Gerger et al. 2010, Jung et al. 2010, Knechtel et al. 2010). Here, we investigate the potential contribution of the four most common PTGS2 SNPs and their haplotypes, in combination with obesity, as prognostic predictors of disease-free survival in newly diagnosed non-metastatic breast cancer.

\section{Materials and methods}

\section{Subjects and study design}

The study population consisted of an on-going prospective hospital-based cohort of Brazilian women with first diagnosis of unilateral breast carcinoma and no identification of distant metastases. Patients were recruited when assigned for curative surgery $(N=713$, either mastectomy or segmentectomy) or neoadjuvant chemotherapy $(N=325)$, as their first therapeutic approach at the Brazilian National Cancer Institute (INCA), during 
the period from February 2009 to April 2013. The study was conducted following the international precepts of ethics in research, including the 1964 Helsinki declaration and its later amendments and of good clinical practice. The authors complied with the Brazilian regulation of clinical research. The study protocol was approved by the Ethics Committees of the Brazilian National Cancer Institute (INCA \#129/08) and of the National School of Public Health (FIOCRUZ/CAAE 55929416.8.0000.5240), and all patients gave written consent to participate. The REMARK guidelines (REporting recommendations for tumor MARKer prognostic studies) were followed (McShane et al. 2005). A description of this breast cancer cohort has already been published (Vieira-Monteiro et al. 2016), but survival data were updated.

\section{Clinical conducts}

Treatments were chosen by the institutional medical staff, according to local standard protocols. In brief, the first therapeutic approach could be curative surgery ( $N=713$, either mastectomy or segmentectomy), which was recommended for all cases of resectable tumor or neoadjuvant chemotherapy $(N=325)$, for patients with locally advanced disease.

Patients initially submitted to curative surgery could be further treated with adjuvant chemotherapy $(61.6 \%)$ or radiotherapy (16.4\%), whereas those with in situ or small tumors $(<2 \mathrm{~cm})$ and no lymph node metastasis received hormonal therapy alone (12.9) or were clinically followed with no secondary intervention (9.1\%).

Patients who initiated treatment with neoadjuvant chemotherapy could be subsequently assigned for curative surgery ( $N=306$, consisting of mastectomy) or for palliative treatment $(N=19$, comprising cases of inoperable tumors or disease progression during neoadjuvant chemotherapy).

The standard chemotherapeutic protocol for both adjuvant and neoadjuvant chemotherapy was CAF-T (3 cycles of cyclophosphamide, doxorubicin and 5 -fluorouracyl, followed by 3 cycles of docetaxel), which accounted for $65.8 \%$ of adjuvant chemotherapy and $90.5 \%$ of neoadjuvant chemotherapy. Alternatively to CAF-T, patients could also be treated with CAF ( 6 cycles; $13.2 \%$ in adjuvant chemotherapy or $2.5 \%$ in neoadjuvant chemotherapy), CA (6 cycles; $14.1 \%$ in adjuvant chemotherapy) or C-T (3 cycles each; 3.4\% in adjuvant chemotherapy or $2.5 \%$ in neoadjuvant chemotherapy). Other protocol options accounted for less than 5\% of either adjuvant or neoadjuvant chemotherapy.
Cardiac function and blood cell counts were evaluated prior to chemotherapy selection and monitored during clinical follow-up.

All patients with HER2+ tumors also received trastuzumab, which was initiated in combination with docetaxel or after completion of chemotherapy. Subsequent hormonal therapy was also prescribed for patients with luminal tumors.

\section{Collection of clinical and histopathological data}

Patients were interviewed to provide information on their clinical history and life-style habits. The variables considered for clinical history were age at diagnosis, menopausal status and comorbidities, including any pre-existing chronic condition under medical treatment. Obesity was the only exception, being defined based on the body mass index (BMI), which was calculated as the weight $(\mathrm{kg})$ divided by the square of height $\left(\mathrm{m}^{2}\right)$. Patients were classified in three groups according to their BMI, as follows: under or normal weight (BMI $\leq 24.9)$, overweight $(25 \leq \mathrm{BMI} \leq 29.9)$ and obese $(\mathrm{BMI} \geq 30)$ (WHO Expert Committee 1995).

Histopathological characterization of breast tumors was performed with biopsies obtained for diagnostic purposes and was based on the 3rd edition of the WHO Classification of Tumors (Ellis et al. 2003) and on the Elston-Ellis histological grading system (Elston \& Ellis 1991). The data on hormone receptors and HER2 status of breast tumors, according to immunohistochemical and fluorescence in situ hybridization analyses were used for surrogate classification of tumor subtypes (Huober et al. 2010). In brief, four subtypes were considered: Luminal A, positive for both estrogen receptor (ER) and progesterone receptor (PR), but negative for HER2; Luminal B, positive for either ER or PR, regardless of HER2 status or positive for the three receptors; HER2-like, negative for both ER and PR, but positive for HER2; and triple-negative, when negative for all the three receptors.

\section{Genotyping analyses}

Peripheral blood samples $(3 \mathrm{~mL})$ were collected from all subjects, and DNA was extracted using the Blood Genomic Prep Mini Spin Kit (GE Healthcare), following the procedures recommended by the manufacturer.

Patients were genotyped for $\operatorname{rs689465}(-1290 A G)$ and rs20417 (-765 GC) using PCR-RFLP (PCR restriction fragment length polymorphism assay), as described previously (Piranda et al. 2010), and for rs689466 
$(-1195 \quad A G)$ and rs5275 (8473 TC) by allelic discrimination using TaqMan SNP Genotyping Assays (Applied Biosystems), as described previously (Festa-Vasconcellos et al. 2012).

\section{Survival outcomes}

Survival analyses were performed for all patients submitted to curative surgery, either as their first therapeutic approach $(N=713)$ or following neoadjuvant chemotherapy $(N=306)$. Total patient follow-up was 77,002 person-months, with a median follow-up time per person of 78 months. Disease-free survival was defined as the primary clinical endpoint of the study. Disease progression was characterized by the occurrence of locoregional or contralateral recurrence of breast cancer or by any distant metastasis. The time to event (TTE) was calculated as the period between the date of surgery and the date of relapse detection, i.e. imaging diagnosis or histopathological characterization of disease progression. Patients were considered disease-free if they had no suggestive clinical symptoms or imaging diagnosis of disease progression until their last medical consult. New primary cancer lesions or deaths by causes unrelated to disease progression were censored in survival analysis. Patients achieving five years of follow-up were also censored.

\section{Statistical analyses}

A descriptive study of the cohort was conducted, presenting relative frequencies for each categorical variable. Individual features were dichotomized according to better- or worse-expected prognostic values and evaluated for their association with PTGS2 genotypes and for their impact on survival outcomes.

Allelic and genotypic frequencies of PTGS2 were derived by gene counting, and the adherence to the HardyWeinberg principle was evaluated by the chi-square test for goodness of fit. Haplotype patterns were inferred using Haploview 4.2 (Haploview internet version), based on the algorithm of expectation and maximization (Barrett et al. 2005). Individual diplotypes were inferred using the Haplo Stats software, version 1.3 (Schaid et al. 2002). The distribution of PTGS2 genotypes according to clinical and histopathological features was evaluated using the chi-square or Fisher's exact tests.

Disease-free survival curves were estimated using the Kaplan-Meier product-limit method, with the influence of individual variables on the mean time to disease progression being evaluated with the two-sided logrank test. The impact of individual variables on diseasefree survival rates was estimated by calculation of their hazard ratios (HR) and 95\% confidence intervals (95\% CI). Variables that significantly affected disease-free survival in the general cohort were included as covariates in multivariate Cox proportional hazards regression models to calculate the adjusted $\mathrm{HR}\left(\mathrm{HR}_{\mathrm{adj}}\right)$ and respective 95\% CI of new potential prognostic factors of breast cancer progression.

All statistical analyses were conducted using SPSS 13.0 for Windows (SPSS). The adequacy of sample sizes for statistical power analyses was evaluated using the online calculators at the website of the University of California San Francisco (http://www.sample-size.net/sample-sizesurvival-analysis/).

\section{Results}

Table 1 presents the main clinical and histopathological characteristics of the study cohort $(N=1038)$, with the distribution of PTGS2genotypesbeingevaluated for patients with available DNA $(N=959)$. Haplotypes $(N=1852)$ were inferred from samples with successful PTGS2 genotyping $(N=926)$, the minimum rate of successful genotyping being $93.5 \%$ for rs5275. A previous description of this cohort formation and clinical characteristics has been already published (Vieira-Monteiro et al. 2016). Here, we added information concerning the frequency of comorbidities, hypertension being the most prevalent, followed by obesity and diabetes. Besides being highly prevalent in the cohort (only 30\% of patients had no prediagnosed conditions), comorbidities were also frequently coexisting, with $21.1 \%$ of patients presenting at least two concomitant conditions. Regarding BMI, most patients were above normal weight (70\%), with 30\% being obese. All PTGS2 SNPs were in Hardy-Weinberg equilibrium, with minor allele frequencies of 0.15 for $\operatorname{rs689465}(-1290 \mathrm{G})$, 0.14 for rs689466 $(-1195 G), 0.25$ rs20417 $(-765 C)$ and 0.37 for rs5275 $(8473 \mathrm{C})$. The four SNPs showed strong linkage disequilibrium, forming a single haploblock with 8 haplotypes, the first 5 summing $93.8 \%$ of the cohort variability.

In order to explore the potential interaction between obesity and PTGS2 SNPs in breast cancer presentation and outcomes, we first evaluated the distribution of clinical features and of PTGS2 SNPs according to obesity (Table 2). Significant differences were found only for age at diagnosis, with obese patients presenting an approximate $7 \%$ decrease in the proportion of patients younger than 
Table 1 Description of the study cohort $(N=1038)$.

\begin{tabular}{|c|c|c|}
\hline Features & $\mathbf{N}$ & $\%$ \\
\hline \multicolumn{3}{|l|}{ Histopathological type } \\
\hline Ductal invasive & 902 & 86.9 \\
\hline Lobular invasive & 58 & 5.6 \\
\hline In situ (ductal or lobular) & 47 & 4.7 \\
\hline Others & 29 & 2.8 \\
\hline \multicolumn{3}{|l|}{ Tumor stage (TNM) } \\
\hline$\leq \mathrm{IIA}$ & 529 & 52.2 \\
\hline$\geq I I B$ & 484 & 47.8 \\
\hline Missing & 25 & \\
\hline \multicolumn{3}{|l|}{ Tumor grade (G) } \\
\hline G1 & 96 & 11.1 \\
\hline G2 & 403 & 46.5 \\
\hline G3 & 367 & 42.4 \\
\hline Missing & 172 & \\
\hline \multicolumn{3}{|l|}{ Tumor subtype } \\
\hline Luminal A & 537 & 57.2 \\
\hline Luminal B & 210 & 22.3 \\
\hline HER2-like & 63 & 6.7 \\
\hline Triple-negative & 130 & 13.8 \\
\hline Missing & 98 & \\
\hline \multicolumn{3}{|l|}{ Comorbidities ${ }^{a}$} \\
\hline None & 341 & 32.8 \\
\hline Hypertension & 516 & 50.2 \\
\hline Obesity & 282 & 30.0 \\
\hline Diabetes mellitus & 137 & 13.4 \\
\hline \multicolumn{3}{|l|}{ BMI } \\
\hline$\leq 18.4-24.9$ & 275 & 29.3 \\
\hline $25-29.9$ & 382 & 40.7 \\
\hline More than 30.0 & 282 & 30.0 \\
\hline Missing & 99 & \\
\hline
\end{tabular}

\begin{tabular}{|c|c|c|}
\hline Genotypes & $N$ & $\%$ \\
\hline \multicolumn{3}{|l|}{ rs689465 } \\
\hline$A A$ & 666 & 72.1 \\
\hline$A G$ & 230 & 24.9 \\
\hline GG & 28 & 3.0 \\
\hline Missing & 35 & \\
\hline \multicolumn{3}{|l|}{ rs689466 } \\
\hline$A A$ & 680 & 73.7 \\
\hline$A G$ & 220 & 23.8 \\
\hline GG & 23 & 2.5 \\
\hline Missing & 36 & \\
\hline \multicolumn{3}{|l|}{ rs20417 } \\
\hline GG & 529 & 57.1 \\
\hline$G C$ & 326 & 35.2 \\
\hline CC & 71 & 7.7 \\
\hline Missing & 33 & \\
\hline \multicolumn{3}{|l|}{ rs5275 } \\
\hline$T T$ & 344 & 38.3 \\
\hline$T C$ & 434 & 48.4 \\
\hline CC & 119 & 13.3 \\
\hline Missing & 62 & \\
\hline \multicolumn{3}{|c|}{ Haplotype } \\
\hline *1 AAGT & 917 & 44.2 \\
\hline *2 AAGC & 287 & 13.8 \\
\hline$* 3$ GACC & 243 & 11.7 \\
\hline *4 AGGT & 299 & 14.4 \\
\hline *5 AACC & 201 & 9.7 \\
\hline *6 AACT & 56 & 2.7 \\
\hline *7 GACT & 23 & 1.1 \\
\hline *8 GAGC & 50 & 2.4 \\
\hline
\end{tabular}

aPatients may present two or more comorbidities concomitantly; bPTGS2 haplotypes composed by rs689465, rs6894656, rs20417, rs5275. $\mathrm{BMI}$, body mass index; HER2, human epidermal growth factor receptor 2 .

45 years and a 10\% increase within 45-59 years, which was the age range with the highest prevalence of obesity (35\%). Such increase in age according to obesity, however, was not maintained for patients older than 50 years.

Second, we evaluated the distribution of PTGS2 SNPs according to histopathological features of breast tumors. Significant differences were found only for rs5275, whose variant genotypes $(T C+C C)$ were significantly associated with positive lymph node status $(\mathrm{OR}=1.33$; $95 \% \mathrm{CI}=$ 1.01-1.74). Nevertheless, the haplotypic distribution showed no significant differences according to histopathological characteristics (data not shown).

Next, we evaluated the influence of clinical and histopathological characteristics, as well as of PTGS2 genotypes and haplotypes, on the risk of disease progression. Loco-regional or contralateral recurrence affected 47 patients, distant metastasis was observed in 165 cases and 135 deaths were recorded. Table 3 shows the results regarding the evaluation of disease-free survival in the complete cohort and according to obesity status.
High tumor stage, defined by $T N M \geq I I B$, neoadjuvant treatment and HER2-like or triple-negative subtypes were significantly associated with shorter disease-free survival for all breast cancer patients in the cohort, regardless of the obesity status. High histological grade $(\mathrm{G} 2+\mathrm{G} 3)$ and age $<45$ years were also good predictors of breast cancer progression in the total cohort, as well as among nonobese patients. Obesity was not associated with disease progression in the present cohort (data not shown). Regarding PTGS2 SNPs, only rs689466 (-1195 $G$ variant) was associated with a significant reduction in disease-free survival, exclusively among obese patients. Accordingly, patients carrying the haplotype $* 4$, which varies in relation to the wild-type sequence of PTGS2 only at rs689466, presented the shortest time to breast cancer progression within PTGS2 diplotypes. All other PTGS2 haplotypes had no significant effects on disease-free survival, regardless of the obesity status.

Figure 1 shows the disease-free survival curves according to rs689466 genotypes in obese patients. 


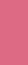

$\stackrel{\substack{\Delta \\ \hdashline}}{ }$

\begin{tabular}{|c|c|c|c|c|c|}
\hline & $\stackrel{\infty}{N} \underset{N}{N}$ & ஸ் & Nִ & 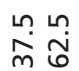 & 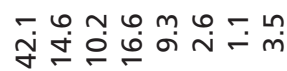 \\
\hline
\end{tabular}

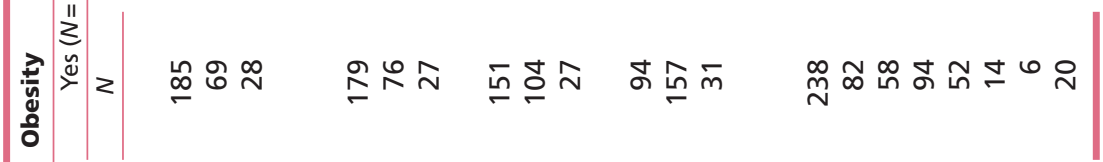

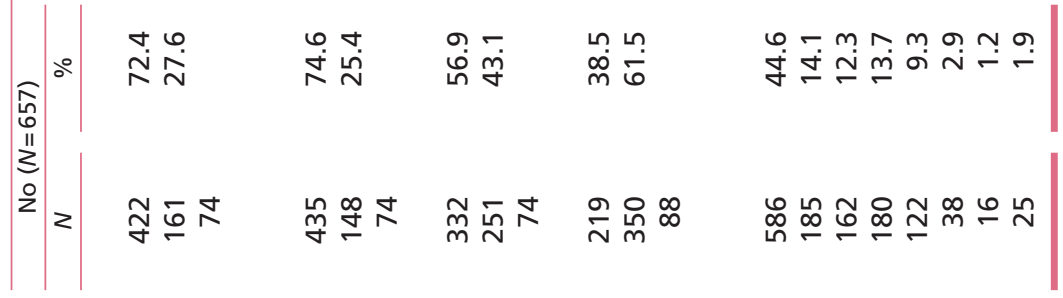

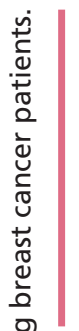

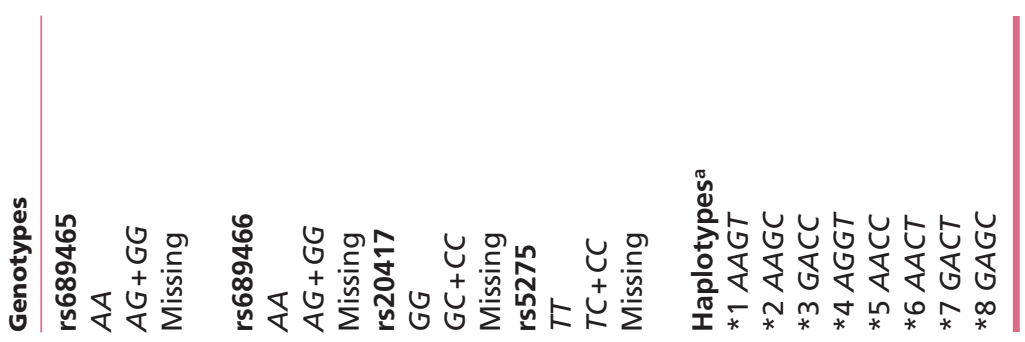

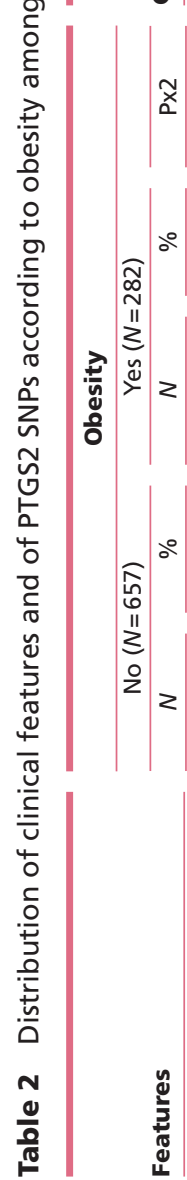

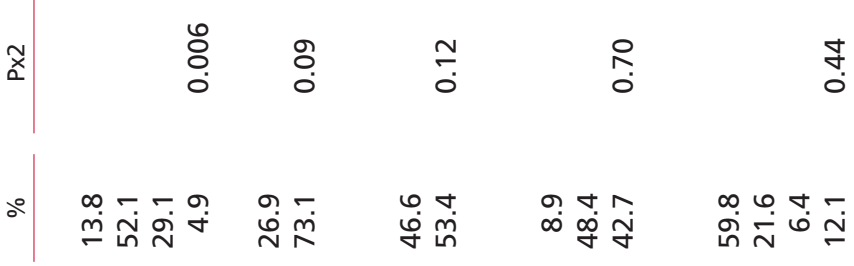

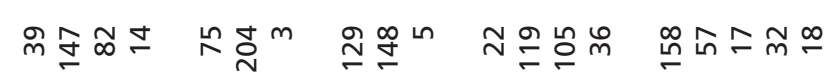

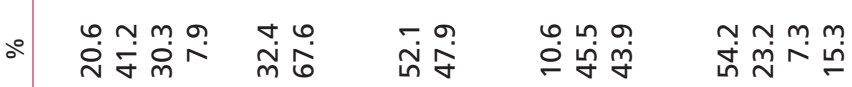

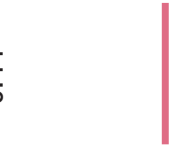




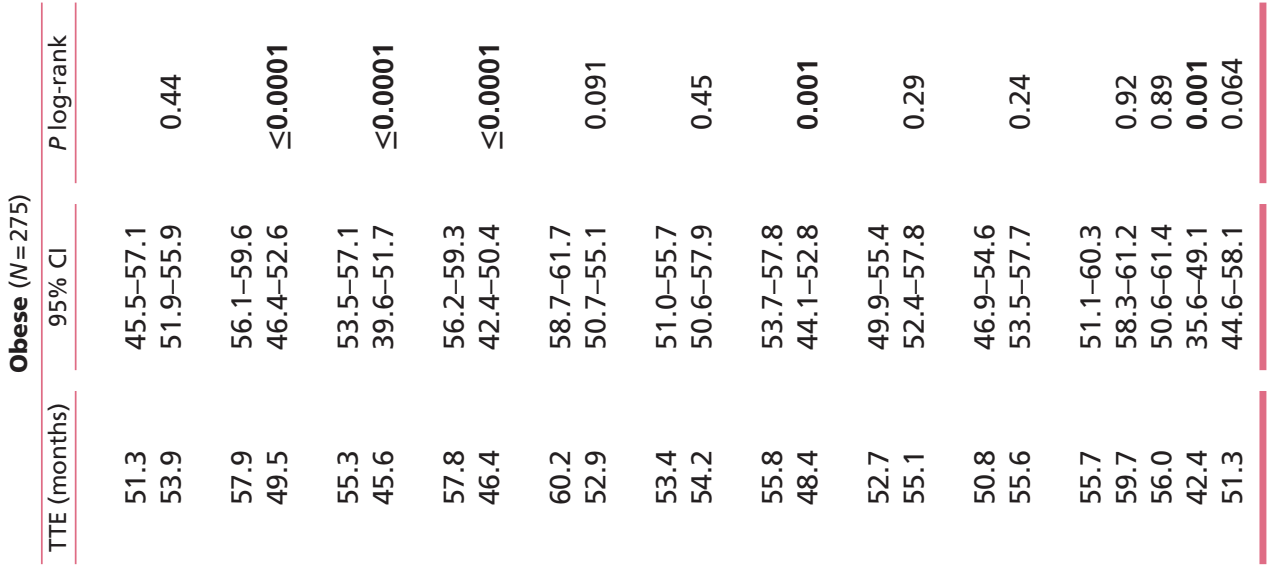

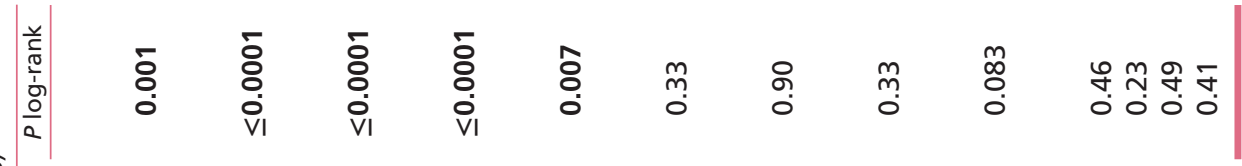

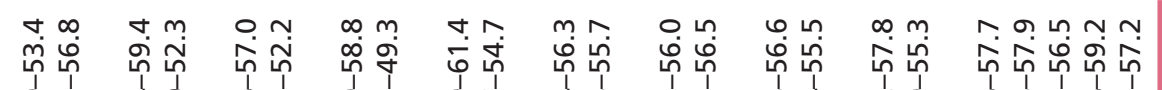
वरे to

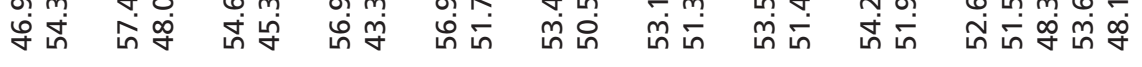

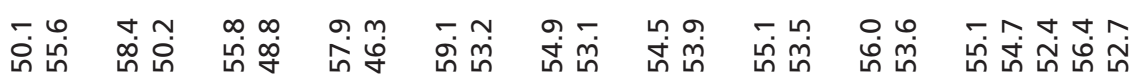

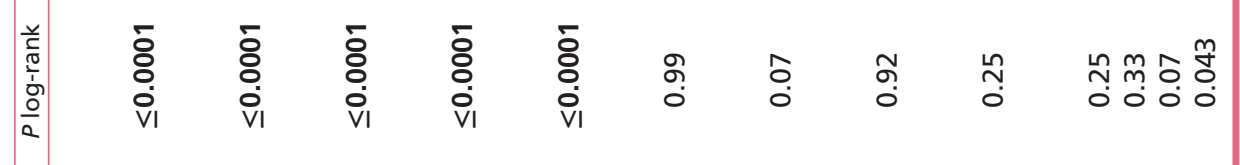

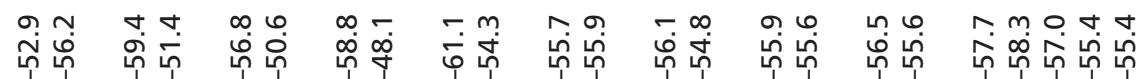
f $\begin{aligned} & 1 \\ & 0\end{aligned}$

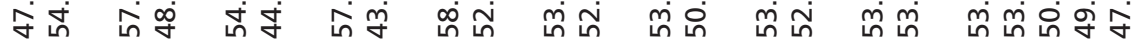

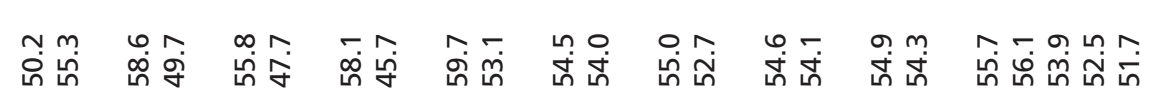
(n)
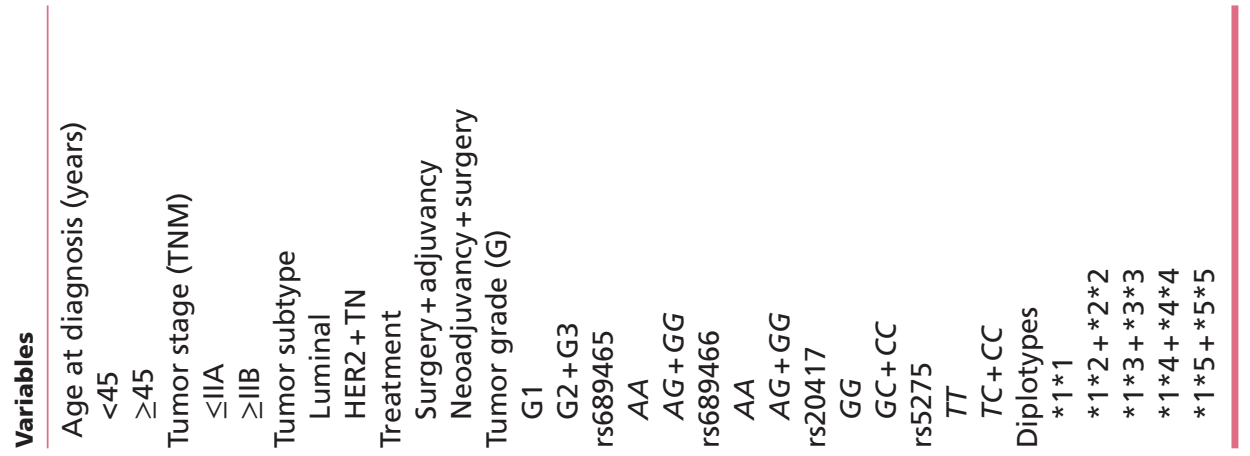
The deleterious impact of variant rs689466 genotypes $(A G+G G)$ on the risk of disease progression was maintained after adjustment for the other significant covariates, even when patients were stratified according to tumor subtypes into luminal or HER2 like and triple negative. Similarly, Fig. 2 shows that the presence of haplotype *4 (in diplotypes ${ }^{*}{ }^{*} 4$ or ${ }^{*} 44$ ) was also responsible for a significant reduction in disease-free survival among obese patients. Again, the effect was maintained when luminal tumors or HER2-like and triple-negative tumors were evaluated separately. Table 4 presents the results of the Cox logistic regression models considering either the rs689466 genotypes or the presence of haplotype * 4 and the other covariates that were associated in univariate analysis (Table 3) with the five-year disease-free survival among obese breast cancer patients in the study cohort. Tumor subtype was maintained in the multivariate model with haplotype *4 although it did not reach statistical significance in this analysis.

Next, the effects of the variant rs689466 genotypes or haplotype * 4 were evaluated according to menopausal status (Fig. 3). No significant differences were detected in premenopausal women (panels $\mathrm{A}$ and $\mathrm{C}$ ), whereas the reduction in disease-free survival associated with either rs689466 variant genotypes or haplotype *4 (diplotypes ${ }^{*} 1{ }^{*} 4$ or ${ }^{*} 44$ ) were confirmed among postmenopausal obese breast cancer patients (panels B and D). Table 5 shows the results of the Cox logistic regression models for the five-year disease-free survival among postmenopausal obese breast cancer patients. The significant impact of rs689466 genotypes or haplotype * 4 on the risk of breast cancer progression was still detectable when luminal or HER2-like and triple-negative tumors were evaluated separately (Fig. 4).

\section{Discussion}

The present study aimed to evaluate the contribution of PTGS2 SNPs, in combination with obesity, as potential prognostic factors of breast cancer outcomes. The study population consisted of a prospective single-institution cohort of breast cancer patients from Brazil with no distant metastasis at diagnosis. Individual clinical histories were fully available, and medical treatments and follow-up routines were standardized, which contributed to minimize heterogeneity and reduce uncontrolled confounding factors. However, a potential disadvantage of this single-institution design, as compared to multi-institutional studies, is the risk of demographic homogeneity, which might lead to results that cannot
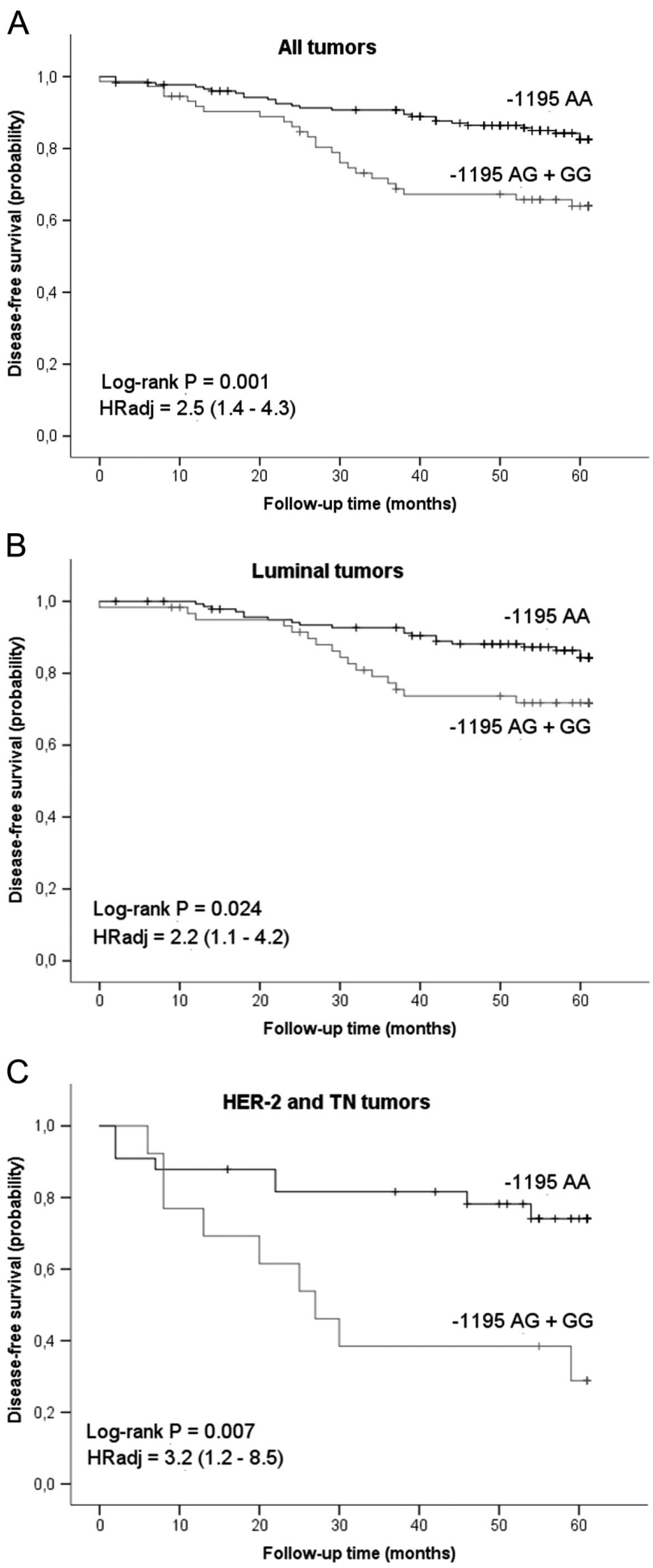

Figure 1

Disease-free survival curves in obese breast cancer patients according to PTGS2 polymorphism rs689466 ( 1195 A $>G)$. Variant genotypes -1195 AG + GG were compared to the wild-type genotype AA in all types of tumor (A), in luminal tumors only (B) and in HER2 and triple-negative tumors (C). Multivariate Cox proportional hazards regression was used to calculate the hazard ratios $\left(H R_{\text {adj }}\right)$, with adjustment for tumor subtype $(A)$, first therapeutic approach and tumor stage based on TNM (A, B and C). 
be further extrapolated. Although we acknowledge this possibility, we expect this risk to be low in our study. INCA is a reference institution for cancer treatment in Brazil, and patients were from different cities of the state of Rio de Janeiro (16.7 million inhabitants). In addition, the Brazilian population is characterized by a high degree of genetic diversity due to intense admixture, especially in the southeast of Brazil, where Rio de Janeiro is located (Parra et al. 2003).

Regarding sample size, recruitment was planned for 1000 subjects, in order to have at least 100 cases of triplenegative tumors, and at least 200 cases of each variant genotype. Such figures were expected to allow robust comparisons of the five-year disease-free survival between genotypes. Because significant results were obtained only among obese patients, who represent $30 \%$ of the cohort $(N=275)$, the obtained data were used to recalculate recommended sample sizes for enough statistical power in the survival analysis (http://www.sample-size.net/ sample-size-survival-analysis/). The required sample sizes for a planned follow-up of five years were calculated to be 245 cases for rs689466 or 247 cases for haplotype * 4 . Both figures are below the actual number of obese patients under analysis, suggesting that the present results can be considered to be within fair levels of confidence.

The evaluation of clinical data indicates a high prevalence of comorbidities, which were often superposed. Hypertension was the most frequent comorbidity, and the figures are similar to those reported for Brazilian breast cancer patients (Lagares et al. 2013), as well as for adult Brazilian women of similar age (Cipullo et al. 2010). The prevalence of diabetes also matched previously reported data involving breast cancer patients from Brazil (Lagares et al. 2013) or adult Brazilian women of similar age (Cipullo et al. 2010). In contrast, the prevalence of obesity in the study cohort was higher than expected for women between 45 and 64 years according to the data of the Brazilian Census (IBGE 2010). Indeed, obesity is a recognized risk factor for the development of breast cancer, especially among postmenopausal women (Yung \& Ligibel 2016).

The evaluation of prognostic impacts of clinical characteristics indicates no significant association between obesity and breast cancer progression in the present cohort. This finding contrasts with previous reports linking obesity with shorter disease-free survival (de Azambuja et al. 2010, Sparano et al. 2012, Pajares et al. 2013, Widschwendter et al. 2015), as well as with increased mortality (de Azambuja et al. 2010, Protani et al. 2010, Sparano et al. 2012, Chan et al. 2014, Widschwendter et al. 2015).
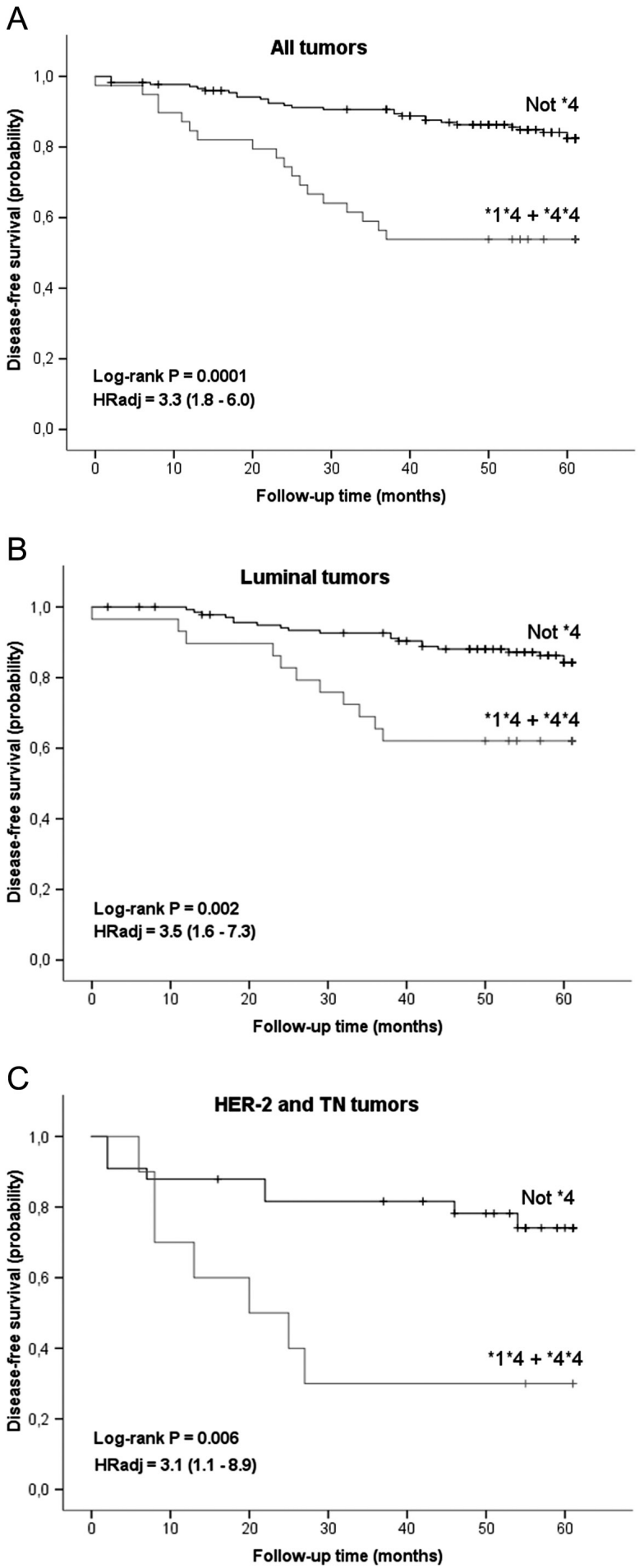

Figure 2

Disease-free survival curves in obese breast cancer patients according to PTGS2 haplotype *4. Diplotypes * $1 * 4+* * 4$ were compared to all other diplotypes not containing haplotype *4 in all types of tumor $(A)$, in luminal tumors only (B) and in HER2 and triple-negative tumors (C). Multivariate Cox proportional hazards regression was used to calculate the hazard ratios $\left(\mathrm{HR}_{\mathrm{adj}}\right)$, with adjustment for the first therapeutic approach (A, B and C), tumor stage based on TNM (A and B) and tumor subtype (A). 
Table 4 Logistic regression models for the five-year disease-free survival in obese breast cancer patients.

\begin{tabular}{l} 
Variables \\
\hline Treatment \\
TNM \\
Tumor subtype \\
A-1195G \\
Treatment \\
TNM \\
Tumor subtype \\
$(* 1 * 4+* 4 * 4)$ vs not *4
\end{tabular}

\begin{tabular}{c}
\hline Coefficient \\
\hline 0.941 \\
0.873 \\
0.834 \\
0.909 \\
1.093 \\
0.802 \\
0.551 \\
1.187 \\
\hline
\end{tabular}

\begin{tabular}{c}
\hline Default error \\
\hline 0.334 \\
0.360 \\
0.308 \\
0.277 \\
0.368 \\
0.384 \\
0.332 \\
0.307 \\
\hline
\end{tabular}

\begin{tabular}{c}
\hline $\boldsymbol{P}$ value \\
\hline 0.005 \\
0.015 \\
0.007 \\
0.001 \\
0.003 \\
0.037 \\
0.097 \\
0.000
\end{tabular}

\begin{tabular}{c}
\hline Hazard ratio \\
\hline 2.563 \\
2.394 \\
2.303 \\
2.481 \\
2.984 \\
2.231 \\
1.735 \\
3.278 \\
\hline
\end{tabular}

\begin{tabular}{c}
\hline $\mathbf{9 5 \%}$ confidence interval \\
\hline $1.331-4.936$ \\
$1.182-4.848$ \\
$1.259-4.211$ \\
$1.441-4.273$ \\
$1.451-6.136$ \\
$1.051-4.734$ \\
$0.905-3.325$ \\
$1.795-5.986$ \\
\hline
\end{tabular}

Nevertheless, Pajares et al. (2013) found a significant deleterious effect on breast cancer outcomes only for patients with $\mathrm{BMI} \geq 35$ when compared to normal or underweight patients. More recently, Widschwendter et al. (2015) confirmed an increase in the rates of breast cancer recurrence and mortality for patients with severe obesity (BMI $\geq 40$ ), but not for those with moderate or slight obesity (BMI 30-39.9). In the present cohort, severe obesity was detected in 24 patients $(2.4 \%)$, whereas 68 (6.7\%) presented moderate obesity (BMI 35-39.9), and 190 (20.2\%) had slight obesity (BMI 30-34.9). Although such proportion is similar to those reported by Pajares et al. (2013) or Widschwendter et al. (2015), the limited number of individuals with severe obesity in the present cohort may have limited the detection of increased recurrence risk. Also, although the histopathological features and treatment conditions were also similar between our study and those by Pajares et al. (2013) or Widschwendter et al. (2015), the latter two involved only patients from clinical trials, and trastuzumab was not included in the therapeutic protocols.

Regarding other clinical and histopathological characteristics, large tumor size, positive lymph node status, high histological grade and negative status for hormone receptors were good predictors of breast cancer progression, as it could be expected based on previous epidemiological studies (Fragomeni et al. 2018). Treatment conducts also affected disease-free survival in the present cohort, with poorer outcomes being observed among patients who received neoadjuvant treatment, as compared to those who were initially treated with curative surgery. Such finding is not in agreement with more recent studies, which indicate therapeutic equivalence between neoadjuvant and adjuvant approaches in breast cancer
A
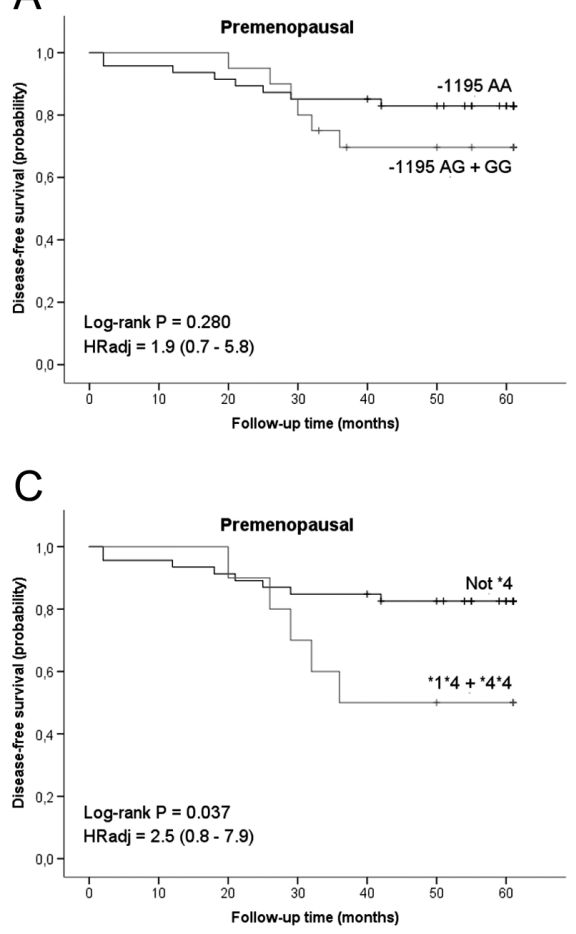
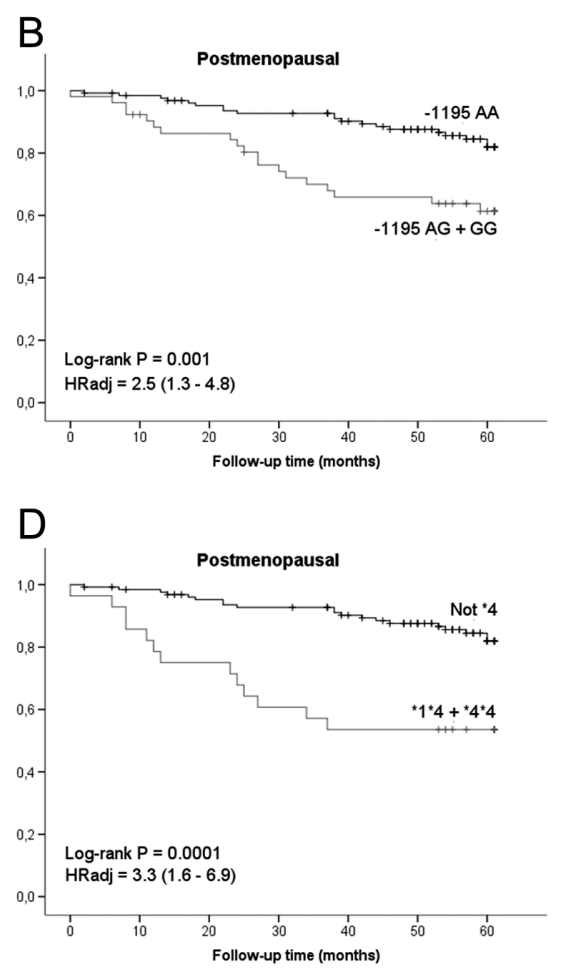

Figure 3

Disease-free survival curves in obese breast cancer patients according to menopausal status and to PTGS2 polymorphism rs689466 (-1195 $A>G)$ or haplotype *4. Premenopausal $(A$ and $C$ ) and postmenopausal patients ( $B$ and $D$ ) were evaluated according to genotypes -1195 AG + GG vs $A A$ ( $A$ and $B$ ) or according to diplotypes $* 1 * 4+* 4 * 4$ vs other diplotypes not containing * 4 (C and D). Multivariate Cox proportional hazards regression was used to calculate the hazard ratios $\left(H R_{a d j}\right)$, with adjustment for first therapeutic approach, tumor stage based on TNM and tumor subtype (A, B, C and D). 
Table 5 Logistic regression models for the five-year disease-free survival in postmenopausal obese breast cancer patients.

\begin{tabular}{|c|c|c|}
\hline Variables & Coefficient & Default error \\
\hline Treatment & 0.762 & 0.380 \\
\hline TNM & 0.886 & 0.419 \\
\hline Tumor subtype & 0.999 & 0.354 \\
\hline A-1195G & 0.931 & 0.324 \\
\hline Treatment & 0.972 & 0.429 \\
\hline TNM & 0.832 & 0.452 \\
\hline Tumor subtype & 0.706 & 0.387 \\
\hline$(* 1 * 4+* 4 * 4)$ vs not $* 4$ & 1.205 & 0.370 \\
\hline
\end{tabular}

treatment (Apuri 2017) and reflects a selective indication of neoadjuvant chemotherapy for patients with locally advanced tumors. In fact, INCA's standard therapeutic conduct for breast cancer recommends to initiate treatment with curative surgery (either segmentectomy or mastectomy) if the tumor is clinically evaluated as resectable. Therefore, the worse disease-free survival associated with neoadjuvant treatment is actually due to worse tumor presentation at diagnosis. The distribution of PTGS2 SNPs in the study cohort, regarding their allele frequencies and haplotypic pattern, was similar to those previously described for a different set of breast cancer patients from Brazil (Piranda et al. 2010) and was not affected by obesity status. The distribution of PTGS2 SNPs according to histopathological features suggested an association between rs5275 variant genotypes $(\mathrm{TC}+\mathrm{CC})$ and positive lymph node status, which had not been detected in a previous study that included some patients

\begin{tabular}{ccccc}
\hline $\boldsymbol{P}$ value & & Hazard ratio & & 95\% confidence interval \\
\cline { 1 - 1 } 0.045 & & 2.143 & & $1.017-4.514$ \\
0.034 & & 2.424 & & $1.067-5.507$ \\
0.005 & & 2.717 & & $1.357-5.438$ \\
0.004 & & 2.537 & & $1.344-4.790$ \\
0.023 & & 2.644 & & $1.141-6.130$ \\
0.066 & & 2.298 & & $0.947-5.575$ \\
0.068 & & 2.027 & & $0.950-4.325$ \\
0.001 & 3.336 & $1.616-6.888$ \\
\hline
\end{tabular}

of the present cohort (Festa-Vasconcellos et al. 2012). Nevertheless, such association was not confirmed when PTGS2 haplotypes were evaluated. Unfortunately, there are no other reports in the literature exploring the association of these four PTGS2 SNPs, or their haplotypes, with histopathological features of breast cancer.

The prognostic evaluation of PTGS2 SNPs or their haplotypes on breast cancer outcomes indicated that the variant rs689466 genotypes, as well as the rs689466containing haplotype ${ }^{*} 4$, were significantly associated with shorter disease-free survival. Such deleterious effect of rs689466 on prognosis, however, was valid only for obese patients, suggesting that its action may depend on the availability of stimulating factors, probably released within the obesity-related inflammatory process. Accordingly, obesity has been associated with increased circulating levels of several growth factors, cytokines and adipokines, including interleukin-6, an inflammatory
A

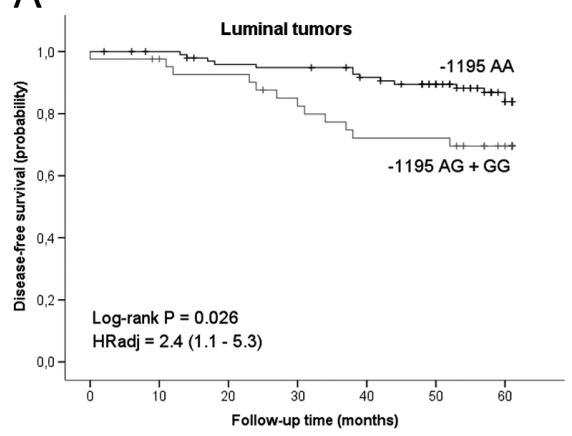

C

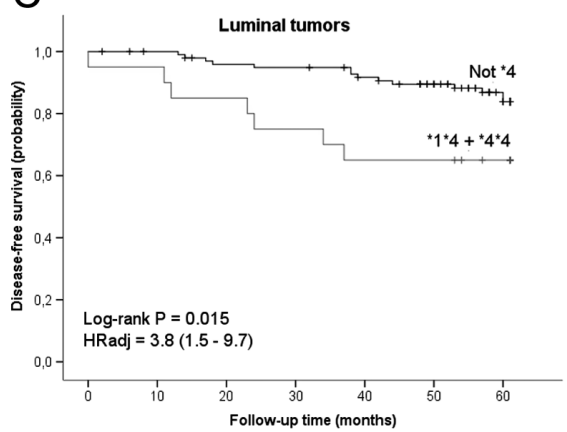

B

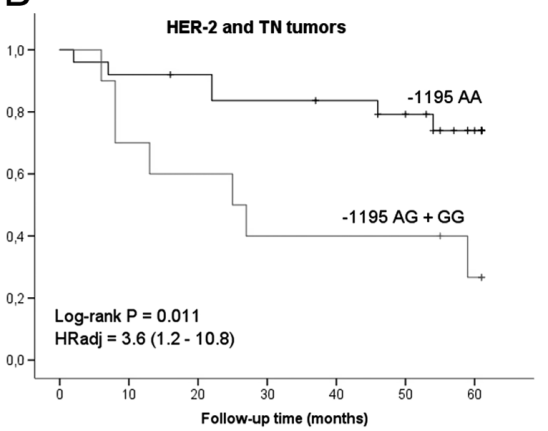

D

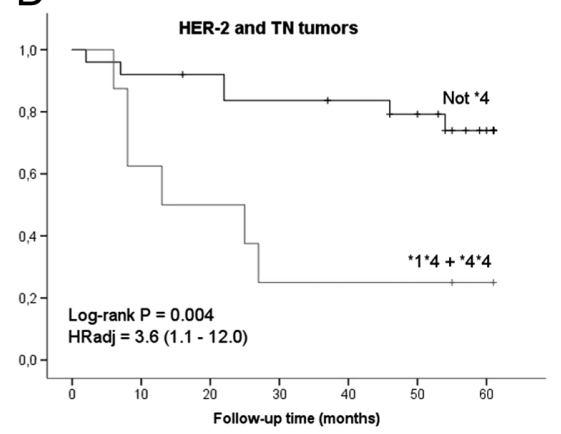

Figure 4

Disease-free survival curves in postmenopausal obese breast cancer patients according to tumor subtype and PTGS2 polymorphism rs689466 (-1195 $A>G)$ or haplotype *4. Luminal tumors (A and $C$ ) or HER2 and triple-negative tumors ( $B$ and $D$ ) were evaluated according to genotypes $-1195 A G+G G$ vs $A A$ ( $A$ and $B$ ) or according to diplotypes $* 1 * 4+* 4 * 4$ vs other diplotypes not containing *4 (C and D). Multivariate Cox proportional hazards regression was used to calculate the hazard ratios $\left(\mathrm{HR}_{\mathrm{adj}}\right)$, with adjustment for the first therapeutic approach (A, B, C and D). 
cytokine secreted by both immune cells and adipocytes, which have been shown to promote PGE2 production via its effects on COX2, resulting in elevated aromatase levels and estrogen production in the breast tissue (Bowers et al. 2015). Moreover, the negative impacts of rs689466 variant genotypes or haplotype * 4 on disease-free survival of breast cancer patients were dependent on the menopausal status, being detected only in postmenopausal women. Such findings appear to reinforce the role of local aromatase induction and the consequent estradiol production by breast adipose tissue after menopause, which can be induced by elevated COX2 and PGE2 in inflamed breast tissue of obese women (Bowers \& deGraffenried 2015).

Interestingly, the deleterious effect of rs689466 variant genotypes or haplotype * 4 on prognosis was observed irrespective of tumor subtype. Although luminal tumors have lower progression rates, they are considered more likely to have its prognosis affected by obesity in postmenopausal women, possibly because they express ER and might be more sensitive to increased aromatase expression and local estradiol release (Bowers \& deGraffenried 2015). Nevertheless, triple-negative tumors have been shown to express high levels of COX2, which correlate with poor survival outcomes (Tian et al. 2017). Therefore, the negative impact of COX2 enzymatic activity in triple-negative tumors appears to be independent from the aromatase-estradiol axis and might be related to stimulation of self-renewal of breast cancer stem cells, as proposed by Tian et al. (2017).

Regarding the potential functional effect of PTGS2 SNP rs689466 on gene transcription, three independent studies used gene-reporter assays to compare the luciferase activity driven by constructs enclosing promoter variants. Zhang et al. (2005), using HeLa cells, showed a 5-6fold increase in the luciferase activity of constructs containing rs689466 $A$ as compared to those with the $G$ variant. This finding, however, was not corroborated in two subsequent studies. Thus, Sakaki et al. (2010), who also used HeLa cells, and Pereira et al. (2014), who used two colon cancer cell lines (HCA-7 and HCT-116), indicated higher transcriptional activity associated with the rs689466 $G$ variant. Taken together, these results from in vitro approaches suggest that the variant genotypes of rs689466 may favor COX2 production and PGE2 synthesis in tumor microenvironment, which might contribute to increase the risk of disease progression. Unfortunately, there are no available data of in vivo or ex vivo studies to corroborate this hypothesis.

The substitution of $-1195 A$ by $G$ (rs689466) apparently eliminates a MYB-binding site (Zhang et al.
2005, Agundez et al. 2014) and creates an E-box motif (Pereira et al. 2014), which recognizes the upstream stimulatory factor (USF), a ubiquitous transcription factor involved on embryonic development, fertility, stress, growth and lipid and carbohydrate metabolisms (Horbach et al. 2015). There are two isoforms of USF: USF1 and USF2, the two proteins apparently occurring in vivo mainly as USF1/USF2 heterodimers (Viollet et al. 1996). USF1 was initially reported as part of the general cellular transcription machinery, but later recognized as a regulator of lipid and glucose metabolism, being linked with familial combined hyperlipidemia (Shi et al. 2008). Genetic variants of USF1 have also been associated with obesity (Choquette et al. 2007). Recently, Laurila et al. (2016) showed that knocking out the orthologous USF1 gene (Usf1-/-) favors lower weight gain and reduced adiposity in mice, either with regular or high-fat diet. Regarding USF2, it has been shown to induce elevated aromatase expression in ectopic endometrium from endometriosis women (Castro et al. 2015).

We hypothesize that obesity, either via its metabolic or inflammatory profile, segregates with elevated USF1 and/or USF2, which stimulate PTGS2 gene transcription in individuals with the rs689466 $G$ variant, thereby leading to increased COX2 production and PGE2 synthesis in tumor cells microenvironment, ultimately favoring disease progression. Such mechanistic hypothesis, however, still needs experimental validation.

In conclusion, the present results suggest a potential contribution of PTGS2 genotyping for additional prognostic evaluation of breast cancer outcomes, especially among obese patients. Such approach, however, also needs to be validated in multi-institutional cohorts with longer clinical follow-ups. Because the present cohort is quite recent, since the study began in 2009 , the total follow-up time is yet limited. In view of this time restraint, overall survival was not evaluated. Also, even for the analysis of disease-free survival, the five-year follow-up is still quite short for patients with early stage tumors, who have lower relapse rates, or for those with luminal breast cancer, who have a natural history of late relapses. It is possible that this relatively short time-frame for survival analyses may have affected the results concerning rs689466 in luminal vs HER2 or triple-negative tumors or compromised the detection of significant effects for the other PTGS2 SNPs. Unfortunately, until the present time, we could not find sources of information on breast cancer cohorts with publically available data on PTGS2 genotypes, clinical parameters including BMI and clinical follow-up, with survival analyses. 


\section{Declaration of interest}

The authors declare that there is no conflict of interest that could be perceived as prejudicing the impartiality of the research reported.

\section{Funding}

This study was supported by Conselho Nacional de Pesquisa e Desenvolvimento (CNPq 474522/2010-5), Fundação Carlos Chagas Filho de Amparo à Pesquisa no Rio de Janeiro (FAPERJ E-26/110.356/2010 and E-26/010.002644/2014) and INCT Para Controle do Câncer (CNPq 573806/2008-0; FAPERJ E26/170.026/2008). D R F-A and H A V-M were awarded scholarships by Coordenação de Aperfeiçoamento de Pessoal de Nível Superior (CAPES).

\section{Author contribution statement}

D R F-A recruited patients, collected clinical and histopathological data, characterized genotypes and haplotypes, performed statistical analyses, generated tables and figures and drafted the manuscript. H A V-M recruited patients, collected clinical and histopathological data and helped with statistical analyses. D N P set the genotyping assays. M S L and T S L $S$ recruited patients and collected clinical and histopathological data. A B conceived the epidemiological design. S S V and J A P contributed to data analysis and interpretation. R V J designed and coordinated the study, analyzed the data, wrote and revised the manuscript. All authors read and approved the final manuscript.

\section{Acknowledgements}

The authors thank Dr Guilherme Suarez-Kurtz for the use of laboratory facilities, and the personnel from the Breast Cancer Hospital (HC3-INCA), and from the National Bank of Tumors in the Brazilian National Cancer Institute (BNT-INCA), for logistic support in sample and data collection.

\section{References}

Abraham JE, Harrington P, Driver KE, Tyrer J, Easton DF, Dunning AM \& Pharoah PDP 2009 Common polymorphisms in the prostaglandin pathway genes and their association with breast cancer susceptibility and survival. Clinical Cancer Research 15 2181-2191. (https://doi. org/10.1158/1078-0432.CCR-08-0716)

Agundez J, Gonzalez-Alvarez D, Vega-Rodriguez M, Botello E \& GarciaMartin E 2014 Gene variants and haplotypes modifying transcription factor binding sites in the human cyclooxygenase 1 and 2 (PTGS1 and PTGS2) genes. Current Drug Metabolism 15 182-195. (https://doi. org/10.2174/138920021502140327180336)

Appleby SB, Ristimäki A, Neilson K, Narko K \& Hla T 1994 Structure of the human cyclo-oxygenase-2 gene. Biochemical Journal $\mathbf{3 0 2}$ 723-727. (https://doi.org/10.1042/bj3020723)

Apuri S 2017 Neoadjuvant and adjuvant therapies for breast cancer. Southern Medical Journal 110 638-642. (https://doi.org/10.14423/ SMJ.0000000000000703)

Barrett JC, Fry B, Maller J \& Daly MJ 2005 Haploview: analysis and visualization of LD and haplotype maps. Bioinformatics 21 263-265. (https://doi.org/10.1093/bioinformatics/bth457)

Bowers LW \& deGraffenried LA 2015 Targeting the COX-2 pathway to improve therapeutic response in the obese breast cancer patient population. Current Pharmacology Reports 1 336-345. (https://doi. org/10.1007/s40495-015-0041-y)

Bowers LW, Maximo IXF, Brenner AJ, Beeram M, Hursting SD, Price RS, Tekmal RR, Jolly CA \& deGraffenried LA 2014 NSAID use reduces breast cancer recurrence in overweight and obese women: role of prostaglandin-aromatase interactions. Cancer Research 74 4446-4457. (https://doi.org/10.1158/0008-5472.CAN-13-3603)

Bowers LW, Brenner AJ, Hursting SD, Tekmal RR \& deGraffenried LA 2015 Obesity-associated systemic interleukin- 6 promotes preadipocyte aromatase expression via increased breast cancer cell prostaglandin E2 production. Breast Cancer Research and Treatment 149 49-57. (https://doi.org/10.1007/s10549-014-3223-0)

Castro J, Araya G, Inostroza P, Hidalgo P, González-Ramos R, Sovino H, Boric MA, Fuentes A \& Johnson MC 2015 Differential expression of upstream stimulatory factor (USF) 2 variants in eutopic endometria from women with endometriosis: estradiol regulation. Biological Research 48 56. (https://doi.org/10.1186/s40659-015-0047-2)

Chan DSM, Vieira AR, Aune D, Bandera EV, Greenwood DC, McTiernan A, Navarro Rosenblatt D, Thune I, Vieira R \& Norat T 2014 Body mass index and survival in women with breast cancer systematic literature review and meta-analysis of 82 follow-up studies. Annals of Oncology 25 1901-1914. (https://doi.org/10.1093/ annonc/mdu042)

Chlebowski RT, Manson JE, Anderson GL, Cauley JA, Aragaki AK, Stefanick ML, Lane DS, Johnson KC, Wactawski-Wende J, Chen C, et al. 2013 Estrogen plus progestin and breast cancer incidence and mortality in the women's health initiative observational study. Journal of the National Cancer Institute 105 526-535. (https://doi org/10.1093/jnci/djt043)

Choquette A, Bouchard L, Houde A, Bouchard C, Pérusse L \& Vohl M-C 2007 Associations between USF1 gene variants and cardiovascular risk factors in the Quebec Family Study. Clinical Genetics 71 245-253. (https://doi.org/10.1111/j.1399-0004.2007.00755.x)

Cipullo JP, Martin JFV, Ciorlia LAS, Godoy MRP, Cação JC, Loureiro AAC, Cesarino CB, Carvalho AC, Cordeiro JA \& Burdmann EA 2010 Prevalência e fatores de risco para hipertensão em uma população urbana Brasileira. Arquivos Brasileiros de Cardiologia 94 519-526. (https://doi.org/10.1590/S0066782X2010005000014)

Crespi E, Bottai G \& Santarpia L 2016 Role of inflammation in obesityrelated breast cancer. Current Opinion in Pharmacology 31 114-122. (https://doi.org/10.1016/j.coph.2016.11.004)

Dai X, Xiang L, Li T \& Bai Z 2016 Cancer hallmarks, biomarkers and breast cancer molecular subtypes. Journal of Cancer 7 1281-1294. (https://doi.org/10.7150/jca.13141)

de Azambuja E, McCaskill-Stevens W, Francis P, Quinaux E, Crown JPA, Vicente M, Giuliani R, Nordenskjöld B, Gutiérez J, Andersson M, et al. 2010 The effect of body mass index on overall and disease-free survival in node-positive breast cancer patients treated with docetaxel and doxorubicin-containing adjuvant chemotherapy: the experience of the BIG 02-98 trial. Breast Cancer Research and Treatment 119 145-153. (https://doi.org/10.1007/s10549-009-0512-0)

Dixon DA 2000 Post-transcriptional control of cyclooxygenase-2 gene expression. The role of the 3'-untranslated region. Journal of Biological Chemistry 275 11750-11757. (https://doi.org/10.1074/ jbc.275.16.11750)

Early Breast Cancer Trialists' Collaborative Group (EBCTCG) 2005 Effects of chemotherapy and hormonal therapy for early breast cancer on recurrence and 15-year survival: an overview of the randomised trials. Lancet 365 1687-1717. (https://doi.org/10.1016/S01406736(05)66544-0)

Ellis IO, Schnitt SJ, Sastre-Garau X, Bussolati G, Eusebi V, Peterse JL, Mukai K, Tabár L, Jacquemier J, Cornelisse CJ, et al. 2003 Tumors of the breast. In Pathology and Genetics of Tumours of the Breast and Female Genital Organs, 3rd ed., pp 9-109. Eds F Tavassoéli \& P Devilee. Lyon, France: IARC Press.

Elston CW \& Ellis IO 1991 Pathological prognostic factors in breast cancer. I. The value of histological grade in breast cancer: experience from a large study with long-term follow-up. Histopathology 19 403-410. (https://doi.org/10.1111/j.1365-2559.1991.tb00229.x)
() 2018 Society for Endocrinology Published by Bioscientifica Ltd. Printed in Great Britain 
Ferlay J, Shin H-R, Bray F, Forman D, Mathers C \& Parkin DM 2010 Estimates of worldwide burden of cancer in 2008: Globocan 2008. International Journal of Cancer 127 2893-2917. (https://doi. org/10.1002/ijc.25516)

Festa-Vasconcellos JS, Piranda DN, Amaral LM, Indio-do-Brasil V, Koifman S \& Vianna-Jorge R 2012 Polymorphisms in cycloxygenase-2 gene and breast cancer prognosis: association between PTGS2 haplotypes and histopathological features. Breast Cancer Research and Treatment 132 251-258. (https://doi.org/10.1007/ s10549-011-1828-0)

Fragomeni SM, Sciallis A \& Jeruss JS 2018 Molecular subtypes and localregional control of breast cancer. Surgical Oncology Clinics of North America 27 95-120. (https://doi.org/10.1016/j.soc.2017.08.005)

Gerger A, Renner W, Langsenlehner T, Hofmann G, Knechtel G, Szkandera J, Samonigg H, Krippl P \& Langsenlehner U 2010 Association of interleukin-10 gene variation with breast cancer prognosis. Breast Cancer Research and Treatment 119 701-705. (https://doi.org/10.1007/s10549-009-0417-y)

Glover JA, Hughes CM, Cantwell MM \& Murray LJ 2011 A systematic review to establish the frequency of cyclooxygenase-2 expression in normal breast epithelium, ductal carcinoma in situ, microinvasive carcinoma of the breast and invasive breast cancer. British Journal of Cancer 105 13-17. (https://doi.org/10.1038/bjc.2011.204)

Harris RE 2014 Cyclooxygenase-2 and the inflammogenesis of breast cancer. World Journal of Clinical Oncology 5 677. (https://doi. org/10.5306/wjco.v5.i4.677)

Horbach T, Götz C, Kietzmann T \& Dimova EY 2015 Protein kinases as switches for the function of upstream stimulatory factors: implications for tissue injury and cancer. Frontiers in Pharmacology 6 3. (https://doi.org/10.3389/fphar.2015.00003)

Huober J, von Minckwitz G, Denkert C, Tesch H, Weiss E, Zahm DM, Belau A, Khandan F, Hauschild M, Thomssen C, et al. 2010 Effect of neoadjuvant anthracycline-taxane-based chemotherapy in different biological breast cancer phenotypes: overall results from the GeparTrio study. Breast Cancer Research and Treatment 124 133-140. (https://doi.org/10.1007/s10549-010-1103-9)

IBGE 2010 Pesquisa de Orçamentos Familiares 2008-2009 antropometria e estado nutricional de crianças, adolescentes e adultos no Brasil. Rio de Janeiro, Brasil: IBGE. (available at: https:// biblioteca.ibge.gov.br/visualizacao/livros/liv45419.pdf)

Iyengar NM, Morris PG, Zhou XK, Gucalp A, Giri D, Harbus MD, Falcone DJ, Krasne MD, Vahdat LT, Subbaramaiah K, et al. 2015 Menopause is a determinant of breast adipose inflammation. Cancer Prevention Research 8 349-358. (https://doi.org/10.1158/1940-6207. CAPR-14-0243)

Jung JH, Chae YS, Moon JH, Kang BW, Kim JG, Sohn SK, Park JY, Lee MH \& Park HY 2010 TNF superfamily gene polymorphism as prognostic factor in early breast cancer. Journal of Cancer Research and Clinical Oncology 136 685-694. (https://doi.org/10.1007/s00432-0090707-0)

Knechtel G, Hofmann G, Gerger A, Renner W, Langsenlehner T, Szkandera J, Wolf G, Samonigg H, Krippl P \& Langsenlehner U 2010 Analysis of common germline polymorphisms as prognostic factors in patients with lymph node-positive breast cancer. Journal of Cancer Research and Clinical Oncology 136 1813-1819. (https://doi. org/10.1007/s00432-010-0839-2)

Lagares ÉB, Santos KdeF, Mendes RC, Moreira FA \& Anastácio LR 2013 Excesso de peso em mulheres com diagnóstico de câncer de mama em hormonioterapia com tamoxifeno. Revista Brasileira de Cancerologia 59 201-210.

Laurila P-P, Soronen J, Kooijman S, Forsstrom S, Boon MR, Surakka I, Kaiharju E, Coomans CP, Van Den Berg SAA, Autio A, et al. 2016 USF1 deficiency activates brown adipose tissue and improves cardiometabolic health. Science Translational Medicine $8323 \mathrm{ra} 13$. (https://doi.org/10.1126/scitranslmed.aad0015)

Li Q, Liu L, Liu Y, Zhou H, Yang Z, Yuan K \& Min W 2015 Five COX-2 gene polymorphisms and risk of breast cancer: an updated meta- analysis based on 19 case-control studies. Medical Oncology 32397. (https://doi.org/10.1007/s12032-014-0397-6)

McShane LM, Altman DG, Sauerbrei W, Taube SE, Gion M, Clark GM \& for the Statistics Subcommittee of the NCI-EORTC Working Group on Cancer Diagnostics 2005 Reporting recommendations for tumor marker prognostic studies (REMARK). Journal of the National Cancer Institute 97 1180-1184. (https://doi.org/10.1093/jnci/dji237)

Moore AE, Young LE \& Dixon DA 2012 A common single-nucleotide polymorphism in cyclooxygenase-2 disrupts microRNA-mediated regulation. Oncogene 31 1592-1598. (https://doi.org/10.1038/ onc.2011.349)

Morris PG, Hudis CA, Giri D, Morrow M, Falcone DJ, Zhou XK, Du B, Brogi E, Crawford CB, Kopelovich L, et al. 2011 Inflammation and increased aromatase expression occur in the breast tissue of obese women with breast cancer. Cancer Prevention Research 4 1021-1029. (https://doi.org/10.1158/1940-6207.CAPR-11-0110)

Mullooly M, Yang HP, Falk RT, Nyante SJ, Cora R, Pfeiffer RM, Radisky DC, Visscher DW, Hartmann LC, Carter JM, et al. 2017 Relationship between crown-like structures and sex-steroid hormones in breast adipose tissue and serum among postmenopausal breast cancer patients. Breast Cancer Research 19 8. (https://doi.org/10.1186/ s13058-016-0791-4)

Pajares B, Pollán M, Martín M, Mackey JR, Lluch A, Gavila J, Vogel C, Ruiz-Borrego M, Calvo L, Pienkowski T, et al. 2013 Obesity and survival in operable breast cancer patients treated with adjuvant anthracyclines and taxanes according to pathological subtypes: a pooled analysis. Breast Cancer Research 15 R105. (https://doi. org/10.1186/bcr3572)

Papafili A 2002 Common promoter variant in cyclooxygenase- 2 represses gene expression: evidence of role in acute-phase inflammatory response. Arteriosclerosis, Thrombosis, and Vascular Biology 22 1631-1636. (https://doi.org/10.1161/01. ATV.0000030340.80207.C5)

Parra FC, Amado RC, Lambertucci JR, Rocha J, Antunes CM \& Pena SDJ 2003 Color and genomic ancestry in Brazilians. PNAS 100 177-182. (https://doi.org/10.1073/pnas.0126614100)

Pereira C, Sousa H, Silva J, Brandão C, Elgueta-Karstegl C, Farrell PJ, Medeiros R \& Dinis-Ribeiro M 2014 The -1195G allele increases the transcriptional activity of cyclooxygenase-2 gene (COX-2) in colon cancer cell lines: -1195AG polymorphism increases COX-2 transcriptional activity. Molecular Carcinogenesis 53 E92-E95. (https:// doi.org/10.1002/mc.22049)

Piranda DN, Festa-Vasconcellos JS, Amaral LM, Bergmann A \& ViannaJorge R 2010 Polymorphisms in regulatory regions of cyclooxygenase- 2 gene and breast cancer risk in Brazilians: a casecontrol study. BMC Cancer 10 613. (https://doi.org/10.1186/14712407-10-613)

Protani M, Coory M \& Martin JH 2010 Effect of obesity on survival of women with breast cancer: systematic review and meta-analysis. Breast Cancer Research and Treatment 123 627-635. (https://doi. org/10.1007/s10549-010-0990-0)

Sakaki M, Makino R, Hiroishi K, Ueda K, Eguchi J, Hiraide A, Doi H, Omori R \& Imawari M 2010 Cyclooxygenase-2 gene promoter polymorphisms affect susceptibility to hepatitis $\mathrm{C}$ virus infection and disease progression: SNP of COX-2 gene protects against HCV infection. Hepatology Research 40 1219-1226. (https://doi. $\operatorname{org} / 10.1111 /$ j.1872-034X.2010.00727.x)

Schaid DJ, Rowland CM, Tines DE, Jacobson RM \& Poland GA 2002 Score tests for association between traits and haplotypes when linkage phase is ambiguous. American Journal of Human Genetics 70 425-434. (https://doi.org/10.1086/338688)

Shi L, Liu S, Nikolic D \& Wang S 2008 High glucose levels upregulate upstream stimulatory factor 2 gene transcription in mesangial cells Journal of Cellular Biochemistry 103 1952-1961. (https://doi. org/10.1002/jcb.21585)

Sparano JA, Wang M, Zhao F, Stearns V, Martino S, Ligibel JA, Perez EA, Saphner T, Wolff AC, Sledge GW, et al. 2012 Obesity at diagnosis is 
associated with inferior outcomes in hormone receptor-positive operable breast cancer. Cancer 118 5937-5946. (https://doi. org/10.1002/cncr.27527)

Tanabe T \& Tohnai N 2002 Cyclooxygenase isozymes and their gene structures and expression. Prostaglandins and Other Lipid Mediators 68-69 95-114. (https://doi.org/10.1016/S0090-6980(02)00024-2)

Tian J, Hachim MY, Hachim IY, Dai M, Lo C, Raffa FA, Ali S \& Lebrun JJ 2017 Cyclooxygenase-2 regulates TGF $\beta$-induced cancer stemness in triple-negative breast cancer. Scientific Reports 7 40258. (https://doi. org/10.1038/srep40258)

Torre LA, Islami F, Siegel RL, Ward EM \& Jemal A 2017 Global cancer in women: burden and trends. Cancer Epidemiology Biomarkers and Prevention 26 444-457. (https://doi.org/10.1158/1055-9965.EPI-160858)

Vieira-Monteiro H de A, Freitas-Alves DR, Sobral-Leite M, Delou JM de A, Goulart-Citrangulo SMT, do Nascimento CT, e Castro TN, Koifman S, Perini JA \& Vianna-Jorge R 2016 Prognostic evaluation of VEGFA genotypes and haplotypes in a cohort of Brazilian women with non metastatic breast cancer. Cancer Biology and Therapy 17 674-683. (https://doi.org/10.1080/15384047.2016.1190486)

Viollet B, Lefrançois-Martinez A-M, Henrion A, Kahn A, Raymondjean M \& Martinez A 1996 Immunochemical characterization and transacting properties of upstream stimulatory factor isoforms.
Journal of Biological Chemistry 271 1405-1415. (https://doi. org/10.1074/jbc.271.3.1405)

WHO Expert Committee 1995 Physical status: the use and interpretation of anthropometry. World Health Organization Technical Report Series 854 1-452.

Widschwendter P, Friedl TW, Schwentner L, DeGregorio N, Jaeger B, Schramm A, Bekes I, Deniz M, Lato K, Weissenbacher T, et al. 2015 The influence of obesity on survival in early, high-risk breast cancer: results from the randomized SUCCESS A trial. Breast Cancer Research 17 129. (https://doi.org/10.1186/s13058-015-0639-3)

Young LE, Sanduja S, Bemis-Standoli K, Pena EA, Price RL \& Dixon DA 2009 The mRNA binding proteins HuR and tristetraprolin regulate cyclooxygenase 2 expression during colon carcinogenesis. Gastroenterology 136 1669-1679. (https://doi.org/10.1053/j. gastro.2009.01.010)

Yung RL \& Ligibel JA 2016 Obesity and breast cancer: risk, outcomes, and future considerations. Clinical Advances in Hematology and Oncology 14 790-797.

Zhang X, Miao X, Tan W, Ning B, Liu Z, Hong Y, Song W, Guo Y, Zhang X \& Shen Y 2005 Identification of functional genetic variants in and their association with risk of esophageal cancer. Gastroenterology 129 565-576. (https://doi.org/10.1016/j. gastro.2005.05.003)

Received in final form 7 December 2017

Accepted 10 January 2018

Accepted Preprint published online 10 January 2018
(C) 2018 Society for Endocrinology Published by Bioscientifica Ltd. Printed in Great Britain 